\title{
Attitudes of students towards blood donation in university of Gondar
}

\begin{abstract}
Introduction: Blood can save millions of life. Blood is the cure, and- man is only source of that cure. The 2012 world blood donor day campaign is "Every blood donor is a hero" focuses on the idea that every one of us can become a hero by donating blood. The percentage of blood collected from voluntary Blood donors and the average annual blood collection rate in Ethiopia are extremely low.

Objective: To assess the attitude of students towards blood donation in Gondar University. Method: A quantitative institution based cross-sectional study design was used to conduct the survey on December 2017 among Geography and Environmental Studies students. There were a total of 15 respondents selected from the Geography department in the university. Systematic random sampling technique was applied to select respondents.

Result: majority of the participants, $11(73.3 \%)$ were males and the age range of most of respondents, $(86.7 \%)$ were from $18-24$ years. $86.7 \%$ of respondents have positive attitude towards blood donation in the department. The survey also found that $73.3 \%$ of the respondents agreed that voluntary donor is the major source of blood donation. Significant numbers of participants in this study are not donating blood either because of not approached to donate or fear of result and consequences of donation.

Conclusion and Recommendations: significant number of students in this study have favorable attitude towards blood donation. Lack of information or not approached to donate, fear for knowing their status and unfit for donate were mentioned as reasons for not donating a blood. As a recommendation, the university should establish or resstrengthen blood donation clubs. Gondar University should work in collaboration with Ethiopian Red Cross society to improve the low level of blood donors through creating awareness and motivating of students.
\end{abstract}

Volume 2 Issue 6 - 2018

\author{
Endalew Terefe \\ Deberetabor University, Ethiopia
}

Correspondence: Endalew Terefe, Deberetabor University, Debretabore City, Ethiopia, Email tendalew@yahoo.co.uk

Received: February 05, 2018 | Published: December 31, 2018
Abbreviations: HIV/ADIS, human immune-virus/acquired immune deficiency syndrome; TTIs, transfusion transmissible infections; VBD, voluntary blood donors; VNRBD, voluntary NONremunerated regular blood donors

\section{Chapter one}

\section{Introduction}

This section presents about the background information about blood donation in relation to the attitudes of the societies in global as well as in the context of our country, Ethiopia. It also presents about the problems regarding attitudes of students in blood donation of students in higher education institutions and the scope as well as the significance of the study

\section{Background of the study}

Blood transfusion is an indispensable component of social health care. It contributes to saving millions of lives each year in both routine and emergency situations, permits increasingly complex medical and surgical interventions and dramatically improves the life expectancy and quality of life of patients with a variety of acute and chronic conditions. ${ }^{1}$ The 2012 world blood donor day campaign is "Every blood donor is a hero" focuses on the idea that every one of us can become a hero by donating blood because we are a part of the society which in turn we are responsible to donate blood to extend the life of others. Every year about 234 million major operations are performed worldwide, of which 63 million people undergoing surgery for traumatic injuries, 31 million for treating cancers and another 10 million for pregnancy-related complications (Tognoni et al, 2011). Blood can save millions of life, and world health organization (WHO) propose countries to focus on young people to achieve $100 \%$ nonremunerated voluntary blood donation by 2020 (Dhingra, 2017). A lack of adequate and safe blood in southern Africa accounts for an estimated 15 percent of anemia related child deaths. Globally there are attempts to meet the Millennium Development Goals 4 (to reduce child mortality), 5 (Improve maternal health) and 6 (to combat HIV/ AIDS, malaria and other diseases) (Millennium campaign, 2017) will not be achieved without persistent efforts by individual countries and the global community to develop safe and sustainable blood supplies. A country needs a blood donation rate of 10 units per 1000 population per year. Now days relative to the pervious, the practice and attitudes of the society to donate blood was changed from time to time.

Patients who require transfusion as part of their clinical management have the right to expect that sufficient blood will be available to meet their needs and to receive the safest blood possible. However, many patients still die or suffer unnecessarily because they do not have access to safe blood transfusion. The timely availability of safe blood and blood products is essential in all health facilities in which transfusion is performed, but in many developing and transitional countries there is a widespread shortfall between blood requirements and blood supplies. According to WHO, countries need voluntary, non-remunerated blood donors are those who donate on their own accord without coercion or incentives, such as money and discourages blood donation for personal gain as it might risk the safety of the blood. ${ }^{1}$ Nevertheless, in many countries especially in developing countries like Africa, paid donors 
and family blood donors continue to make up a large percentage of blood donations. ${ }^{2}$ With regards to sustainable supplied blood at the blood bank, peoples with less income and education level face greater obstacles accessing health services than their well-off counterparts when most of the blood is donated through payment. Accordingly most of the blood was donating by family replacement in many health centers, acquiring $100 \%$ voluntary, non-remunerated donors is a challenge for many countries. For a country to maintain a sustainable blood supply only 1 to 3 percent of a country's populations need to donate blood. Blood donation rates are considerably less and relatively unsafe in developing countries. ${ }^{2}$ Sub-Saharan Africa is home to 14 percent of the world's population, yet total blood donations are estimated to be 6.3 percent of the total global blood donations. ${ }^{3}$

In Ethiopia, there has been gross inadequacy and in-equitability in access to blood. The national requirement for blood in Ethiopia is between $80,000-120,000$ units per year but only $43 \%$ is collected. From the total units to be collected, 10 units/1000 population, only 0.3 units/1000 people were collected. This indicates the severe shortage of blood supplies for the vast majority of the population. Key challenges to progress included a relatively high prevalence of HIV, poor community awareness of the importance of VNRBD with a consequent lack of voluntary donors, social taboos and misconceptions about blood donation within the community. The percentage of blood collected from voluntary Blood donors and the average annual blood collection rate in Ethiopia are extremely low. Out of the 44 WHO African countries who reported the percentage of VNRBD, with $22 \%$ of blood being donated by VBD in Ethiopia, the country is classified among countries who have least number of VBD (Group C,countries with $<50 \%$ voluntary blood donors ). Similarly, the average annual blood collection rate in the Region in 2006 was 4.15 units per 1000 population, ranging from $0.39 / 1000$ in Ethiopia to $34.77 / 1000$ in Mauritius. ${ }^{4}$ Its limited supply were directly related with the attitudes of the society, however, voluntary blood donors donate blood for altruistic reasons and receive no reward except personal satisfaction in helping to save lives and improve the health of individuals they will never meet. While they choose to donate their blood out of a sense of social responsibility, recognition of the importance of their individual donations and appreciation by the blood service and wider community help to create a sense of belonging to a special group of people. Even longstanding donors may need to be reminded of the very tangible difference they have made to other people's lives by donating their blood and through their wider role in society as role models and agents of health promotion. Therefore, students in the higher educational institution as a part of a society have play a vital role regarding with the changing of the attitudes of the whole community being as a role model and actors of donating blood in our country which in turn helps to promote health care services. ${ }^{1}$ To the best of my knowledge, there is no data regarding blood donation on youth population such as university students in Ethiopia as far as the voluntary blood donors are mostly adult populations. Hence, this paper explored the attitude in relation to practice of Gondar University Geography students on blood donation.

\section{Statement of the problem}

Blood transfusion saves lives and improves health, but many patients requiring transfusion do not have timely access to safe blood. The donor is donating for it as it will be used in saving lives of his fellow beings. He himself may use the same during his own need. So, today's donor may be tomorrow's recipient. Without their humane gifts of noble donors, that also from the heart, many lives might have lost for want of blood. Therefore, blood donation is the most generous and biggest ever contribution to mankind and the young generation should be motivated to carry, out this generous activity. Fear of needles, pain, sight of blood, future weakness, and possible ill effects, objection from elders, ignorance and illiteracy etc are all reasons for many people who are hesitant in donating blood. All these attitudes and misconceptions are to be removed in order that adequate amount of blood is made available at blood banks for saving the patients. ${ }^{1}$ In Ethiopia, the attitude of the society is still negative and neglected due to the reasons like lack of awareness, fear of future weakness after they donate blood, and more carelessness to donate blood. Hence, these problems also appear in the students of higher institutions of our country. To ensure safe, adequate and sustainable blood supplies all over the country, the students in University have a significance role in different ways. Even if the students have knowledge about blood donation, in practice and initiating the community to donate blood is very low. As we know students in University are too high in number, but they are not donate blood as far as they are vital to mobilize the community towards voluntary blood donation. So they have to be in front to practice and show as well as overcome awareness and attitude about the importance of blood donation. Therefore, studies conducted in Addis Ababa regarding with blood donation emphasis only on the practice and associated factors among health workers. So far no study has been conducted to investigate the attitudes of students in Gondar University. Therefore, this study intended to fill the gaps in understanding the attitudes of students regarding with the voluntary blood donation and its associated factors in Gondar University by taking Geography department as a case study.

\section{Objective of the Study}

General objective: To assess attitude of the students towards blood donation in University of Gondar of Geography Department.

\section{Specific objectives}

I. To assess factors associated with attitudes of students to donate blood

II. To assess their level of attitude and practice of donating blood

\section{Significance of the study}

Blood donation is a self-initiated volunteer service. However, there is no sufficient data throughout Ethiopia including the study area to have adequate blood supply for acute case management and this study will find the present situation of attitude with regards to their practice related to blood donation in students of Gondar University. By doing so, the attitude with regards to practice of students in Higher Education Institutions is very important to improve blood donation all over the country. Therefore, the purpose of this study is to assess the attitude of Students in Gondar University. Moreover, the results of project may help in program formulation for concerned people and organizations to create awareness and incorporate all higher education students in regular donation activity and educate the public about the importance of blood donation and the risks associated with blood donation.

\section{Scope of the Study}

The study was focused in assessing the attitudes of students in blood donation to save the lives of other and their practices in Gondar University in the College of Social Science and the Humanities in Geography department second year students in November 2017 taking as a case study. The study was taking only 15 students as a sample size for analyzing the attitudes of the students towards blood donation in the study area. 


\section{Chapter Two}

\section{Literature review}

Overview and Magnitude of Knowledge Attitude and Practice of Blood Donation WHO recognized the existence of a significance dependency on family/relative replacement and remunerated donors in developing countries in the Melbourne declaration and advocates the establishment of national blood transfusion services that functions on the basis of voluntary, non-remunerable blood donation by member states. ${ }^{5}$ Low levels of knowledge and practice were observed in a number of published studies across the developing world. A study conducted among Health Science students in South India revealed that only $42.7 \%$ of the respondents have acquired good knowledge on blood donation similarly larger proportion of respondents $(62 \%)$ never donated blood in their entire life. However, an encouraging figure $(87.3 \%)$ was observed as having a positive attitude towards blood donation within the same study. A similar study, to determine the association between knowledge level and other associated factors like gender, among Indian Medical students revealed the prevalence of blood donation rate of among students were only $13.1 \%$. Although this is far less compared to the estimated $60 \%$ in developing countries, the findings are much closer to the study conducted by Pravin and Keerti (Mauka, 2016). In another but similar study conducted on physicians in Nigerian tertiary health facility indicates that, physicians have good knowledge of voluntary blood donation and a positive attitude towards blood donation. ${ }^{6}$ According to this study, $41.4 \%$ of physicians had donated blood in the past which is a bit higher compared to the previous studies in India. 8.6\% of respondents practiced blood donation more than three times a year. Among the overall donors, majority (53.4\%) donated based on sense of voluntarism. ${ }^{6}$

\section{Factors affecting attitude and practice of blood donation}

As Amit and Aseem explained in their study, the awareness of blood donation was found to be increased when the level of education is getting higher. This finding was also supported with a study conducted on Tanzania University Medical students which revealed as knowledge is statistically associated with year of study but in contrary with the findings of Benedict $\mathrm{N}$ and Usimenahon A, where they found out that educational status and staff category did not have significant association with the practice of blood donation. This is also supported by Salaudeen and Odeh with their study on Knowledge and behavior in which they observed literacy level does not affect the knowledge of the respondents. On the other hand those three studies are in agreement when it comes to the reason for non-donation. All of them found that lack of awareness is the main cause of non-donation by non-donors. ${ }^{7}$ On the other hand, contrary to the above findings, a study performed by Manikandan, Srikumar and P Ruvanthik among 400 health care professionals in India found that the reasons for non-donations were no one has ever asked to donate blood rather than luck of awareness. ${ }^{8}$ A study conducted on knowledge, attitude, and practice (KAP) of voluntary blood donation among medical students in India concluded that medical students are well aware regarding blood donation and have positive perception. Nevertheless, very few proportion practiced blood donation. Moreover, Nigerian physicians and health care workers where males are highly likely to donate blood than fema2. les. ${ }^{8}$ In contrast to this, a study conducted on Knowledge, Attitude, and Practice of Voluntary Blood Donation among Healthcare Workers at the University of Benin Teaching Hospital revealed that there is a significant association between blood donation practice with category of staff and level of education. ${ }^{6}$ Among the respondents only $22.1 \%$ of them have donated blood in the past, out of which $52.8 \%$ were as family replacement and $41.7 \%$ voluntary despite the fact that all study participants are within the age range of potential donors (Ibid, 2013). Purushottam observed a statistically significant association between knowledge of blood donation and students from different specialties on their study over KAP of blood donations among Medical students in India. ${ }^{8}$ Socio demographic status such as age and ethnicity did not show significant relationship with knowledge about voluntary blood donation according to a study carried out by Salaudeen and Odeh on Knowledge and behavior towards voluntary blood donation. ${ }^{9}$ Similarly knowledge level and gender do not show any statistical association in a study conducted among medical students in south Indi. In fact this find was also supported by a study carried out in Chile. ${ }^{10}$ Another research done on nursing students by Pravin N Yerpude1, Keerti S Jogdand in India revealed that majority $87.23 \%$ of students never donated blood which is significantly low compared to other studies. In this study the main reasons stated by non-donors for not donating blood were $(29.27 \%)$ students never thought about donating blood and due to fear of sickness or complications which contradicts the findings of the above studies. ${ }^{11}$

\section{Chapter three}

\section{Research methodology}

\section{Research design}

The design of this study is cross-sectional with quantitative data collection methods was employed. The study inclusion criteria were having attended for at least 1st year, regular students of the academic year 2016/17 in Marki Campus of University of Gondar. In addition, to conduct the intended study, quantitative research approach was used in presenting the primary data which were collected through questionnaire. The study was conducted in University of Gondar of College of Social Science and the Humanities in department of Geography and Environmental Studies in Gondar, Ethiopia. The study was conducted in November 2017.

\section{Data collection instruments}

The study was employed questionnaire in order to gather quantitative data from the students'. The questionnaire was developed to gather reliable quantitative data and information from the students about blood donation attitudes and their practices. The questionnaire consist only closed-ended questions.

\section{Sources of data}

The study employed both primary and secondary source of data. The primary data were gathered via questionnaire. The researcher also gathered secondary data from the federal, regional government documents, reports, different books, published and unpublished papers and journals regarding to blood donation.

\section{Sampling procedure and sample size determination}

In the selection of student respondents, purposive sampling technique was used to select Geography and Environmental Studies department students who were second year whose total number are 60 from the College of Social Science and the Humanities. In addition the study populations were all students of the department who were currently attending their second year programs. Therefore, due to the time constraint and as it is enough for clearly understand the attitudes of the students about blood donation; the researcher was picked up only 15 students to analysis the intended problem. Thus, by using systematic random sampling method those 10 students were selected for the total listed students. 


\section{Methods of data analysis and interpretation}

Quantitative data obtained using questionnaire were analyzed using descriptive statistics including frequency and percentages. In addition, data presentation was used tables and figures to form the basis for results and discussions to answer the research questions.

\section{Chapter four}

\section{Data analysis and interpretation}

\section{Introduction}

This section presents and analyses the data collected and discusses it accordingly. First, the demographic profile of respondents is analyzed and presented followed by the attitudes of students towards blood donation. Both are analyzed using frequency tables and percentages.

\section{Demographic profile of the respondents}

The following table summarizes the demographic profile of respondents by sex, age, religion, ethnicity and original residence. Of the total 15 respondents, most $13(86.7 \%)$ were youths and their age ranges from 18 to 24 years. From the total participants, $11(73.3 \%)$ were male students, $10(66.7 \%)$ were orthodox religion followers, 12 $(80 \%)$ were Amhara in their ethnicity and $9(60 \%)$ were came from urban areas (Table 1).

Table I Socio-demographic profile of the respondents

\begin{tabular}{|c|c|c|c|}
\hline $\begin{array}{l}\text { General } \\
\text { characteristics }\end{array}$ & $\begin{array}{l}\text { Specific } \\
\text { demographic } \\
\text { features }\end{array}$ & Frequency & Percentage \\
\hline \multirow[t]{3}{*}{ Sex } & Male & 11 & 73.3 \\
\hline & Female & 4 & 26.7 \\
\hline & Total & 15 & 100 \\
\hline \multirow[t]{4}{*}{ Age } & $18-24$ & 13 & 86.7 \\
\hline & $25-30$ & 2 & 13.3 \\
\hline & $>30$ & - & - \\
\hline & Total & 15 & 100 \\
\hline \multirow[t]{6}{*}{ Religion } & Orthodox & 10 & 66.7 \\
\hline & Muslim & 2 & 13.3 \\
\hline & Catholic & - & \\
\hline & Protestant & 3 & 20 \\
\hline & Other & - & - \\
\hline & Total & 15 & 100 \\
\hline \multirow[t]{5}{*}{ Ethnicity } & Amhara & 12 & 80 \\
\hline & Oromo & 1 & 6.7 \\
\hline & Tigre & - & - \\
\hline & Other & 2 & 13.3 \\
\hline & Total & 15 & 100 \\
\hline \multirow[t]{3}{*}{$\begin{array}{l}\text { Original } \\
\text { Residence }\end{array}$} & Urban & 9 & 60 \\
\hline & Rural & 6 & 40 \\
\hline & Total & 15 & 100 \\
\hline
\end{tabular}

Source: Survey on Dec, 2017.

\section{Levels of attitude towards blood donation}

As indicated from table 2 above, $13(86.7 \%)$ of the respondents said that donating blood is good or have positive attitude towards blood donation which is lower than a study conducted among health science students in India $92.5 \%$ of had favorable attitude towards blood donation ${ }^{12}$ but it is better than the study conducted on medical undergraduate students in Nigeria $68.2 \%$ of had good attitude towards blood donation. ${ }^{13}$ This may be due to the fact that most female's relative males perceive that they are not fit to give blood in our culture. Besides, the information access may not as equal as males. In this study $73.3 \%$ of the students replied that voluntary donor is the best source blood donation in the study area. A study conduct in Tanzania on students of the university $83.4 \%$ revealed that the major source of blood donation is voluntary donor. ${ }^{7}$ With regards to donation causes for disease acquisition, majority $66.7 \%$ were accepted that it is a cause for disease acquisition after blood donation. It is basically related with the level of knowledge of the students regarding with the donation of blood. In contrast to this, a study conducted on Knowledge, Attitude, and Practice of Voluntary Blood Donation among Healthcare Workers at the University of Benin Teaching Hospital revealed that there is a significant association between blood donation practice with category of staff and level of education. ${ }^{6}$

Table 2 Attitude towards blood donation among students of Gondar University

\begin{tabular}{|c|c|c|c|}
\hline General characters & $\begin{array}{l}\text { Specific } \\
\text { characters }\end{array}$ & Frequency & Percentage \\
\hline \multirow[t]{3}{*}{$\begin{array}{l}\text { What do you think } \\
\text { about blood donation }\end{array}$} & Good & 13 & 86.7 \\
\hline & $\mathrm{Bad}$ & - & - \\
\hline & No idea & 2 & 13.3 \\
\hline \multirow[t]{2}{*}{$\begin{array}{l}\text { What do you think } \\
\text { of the best source of } \\
\text { blood donation }\end{array}$} & $\begin{array}{l}\text { Voluntary } \\
\text { donor }\end{array}$ & 11 & 73.3 \\
\hline & $\begin{array}{l}\text { Replacement } \\
\text { donor }\end{array}$ & 4 & 26.7 \\
\hline \multirow[t]{3}{*}{$\begin{array}{l}\text { Does donation case } \\
\text { disease acquisition }\end{array}$} & Yes & 10 & 66.7 \\
\hline & No & 5 & 33.3 \\
\hline & I don't know & - & - \\
\hline \multirow[t]{3}{*}{$\begin{array}{l}\text { What can happen to a } \\
\text { blood donor during or } \\
\text { after donation }\end{array}$} & $\begin{array}{l}\text { Contract } \\
\text { infection }\end{array}$ & 4 & 26.7 \\
\hline & $\begin{array}{l}\text { Temporary } \\
\text { weakness }\end{array}$ & 9 & 60 \\
\hline & Fall sick & 2 & 13.3 \\
\hline \multirow[t]{3}{*}{$\begin{array}{l}\text { Should patient relative } \\
\text { be asked to donate }\end{array}$} & Yes & 12 & 80 \\
\hline & No & 2 & 13.3 \\
\hline & I don't know & 1 & 6.7 \\
\hline \multirow{2}{*}{$\begin{array}{l}\text { Are you willing to } \\
\text { donate blood in the } \\
\text { future }\end{array}$} & Yes & 15 & 100 \\
\hline & No & - & - \\
\hline $\begin{array}{l}\text { Reasons for non- } \\
\text { donation }\end{array}$ & $\begin{array}{l}\text { not } \\
\text { approached } \\
\text { to donate }\end{array}$ & 8 & 53.3 \\
\hline
\end{tabular}


Table Continued....

\begin{tabular}{|c|c|c|c|}
\hline General characters & $\begin{array}{l}\text { Specific } \\
\text { characters }\end{array}$ & Frequency & Percentage \\
\hline & $\begin{array}{l}\text { Unfit to } \\
\text { donate }\end{array}$ & 2 & 13.3 \\
\hline & $\begin{array}{l}\text { Fear of } \\
\text { needle }\end{array}$ & I & 6.7 \\
\hline & $\begin{array}{l}\text { fear of } \\
\text { result and } \\
\text { consequence } \\
\text { of donation }\end{array}$ & 4 & 26.7 \\
\hline
\end{tabular}

Source: Survey on Dec, 2017.

$60 \%$ of the participants agreed that temporary weakness were occurred during or after blood donation. It is the fact that donating blood is occasionally leads to weak but accordingly it is directly related to the attitude towards blood donation. In this study, $80 \%$ of respondents said that patient relatives should be asked to donate which is lower than the study conducted on physician in Nigeria (90.7\%) and health workers in Benin Teaching Hospital in Nigeria (89\%). ${ }^{6}$ As to their attitude on blood donation, all of the respondents replied that they are willing to donate in the future in the study area. This is higher than study conducted among health science students of India University which is $23.4 \%$, ${ }^{7}$ and a study conducted on physician of University of Benin Teaching Hospital in Nigeria (41.4\%). ${ }^{6}$ This is due to the fact that students have better exposure to donate blood in the future than other communities. Similar to other studies, significant numbers of participants in this study are not donating blood either because of not approached to donate or fear of result and consequences of donation. Among those who didn't ever donated blood, not approached to donate by $53.3 \%$, fear of result and consequences of donation by $626.7 \%$, and unfit to donate by $13.3 \%$ were mentioned as reasons for not donating a blood. This is comparable with many researches listed below. Significant number of researchers concluded that people are not donating blood because they fear of contracting disease like HIV and hepatitis ${ }^{14}$ lack of information ${ }^{15}$ donating blood lead to anemia and decrease immunity, reduce blood amount and libido (Olaiya et al, 2010) and fear of knowing ones investigation result. Majority of blood donors in this study were motivated by moral duty. Others were motivated by interest for maintaining one's health and accompanying others. Researchers in different parts of the world also concluded that people donate blood for humanity purpose, ${ }^{16,17}$ other purposes like getting gift and to help relatives.

\section{Chapter five}

\section{Conclusion and recommendations}

As far as the study was delimited to very small number of students which is not a representative of the whole student in the university, the term paper by taking 15 students as a sample found that significant number of students in this study have favorable attitude towards blood donation. As per the general knowledge of the students, voluntary donor is the main source of blood donation in the study area where majority of blood donors were motivated for moral purpose but the survey found that temporary weakness were the pain during or after donating blood.. Lack of information or not approached to donate, fear for knowing their status and unfit for donate were mentioned as reasons for not donating a blood.

\section{Recommendations}

Based on the findings of the survey the following recommendations are made:

I. The university should establish or res-strengthen blood donation clubs.

II. Gondar University should work in collaboration with Ethiopian Red Cross society to improve the low level of blood donors through creating awareness and motivating of students.

III. Intervention activities to bring about behavioral changes among the students on the wider benefit of blood donation for donors and community are recommended.

IV. Clubs in the university should organize different events to build students attitude positively and to increase the number of blood donors.

V. Further study needs to be conducted to explore factors associated with blood donors by taking a representative number in the university

\section{Limitation of the study}

As a matter of fact, the sampling of the participants in all of the campus of the university in general and the whole number of the students of one department in particular was a difficult task due to time limitation. With this limitation the sample which was taken in the survey was not representative simply it helps to give an insight regarding with the attitude of the students towards blood donation in the study area.

\section{Acknowledgments}

None.

\section{Conflicts of interest}

The author declares there is no conflict of interest.

\section{References}

1. WHO. Towards $100 \%$ voluntary blood donation: a global framework for action, WHO press, Geneva. 2010.

2. UNICEF WHO UNAIDS, "Towards universal access: Scaling up priority HIV/AIDS interventions in the health sector," Progress Report. 2010.

3. V Iajya. The effects of information, social and economic incentives on voluntary undirected blood donations: Evidence from a randomized controlled trial in Argentina. No. w18630," National Bureau of Economic Research. 2012.

4. PMJB Tapko, AJ Diarra-Nama. Report of the 2006 Survey on Status of Blood Safety in the Who African Region. 2009.

5. CSA. Central Statistical Agency report, Ethiopia demographic and health survey End Poverty, "Millennium campaign. 2017.

6. Benedict N, Usimenahon A, Alexander N. Knowledge, Attitude, and Practice of Voluntary Blood Donation among Healthcare Workers at the University of Benin Teaching Hospital, Benin City, Nigeria. Journal of Blood Transfusion. 2013;10:115-120.

7. Amit A, Amit G, Gauravi D. Knowledge, attitude, and practice of voluntary blood donation among medical students of PDU medical college India Rajkot. International Journal of Current Research. 2014;6:6839-6841.

8. Manikandan S, Srikumar R, Ruvanthika PN. A Study on Knowledge, Attitude and Practice on Blood Donation among Health Professional Students in Chennai, Tamil Nadu, South India. International Journal of Scientific and Research Publications. 2013;3:2250-2253.

9. Salaudeen AG, Odeh E. Knowledge and behavior towards voluntary 
blood donation among students of a tertiary institution in Nigeria Nigerian Journal of clinical practice. 2011;14:303-307.

10. Purushottam AG, Deepak BP. Knowledge and Attitude about Blood Donation Amongst Undergraduate Students of Pravara Institute of Medical Sciences Deemed University of Central India. Annals of Tropical Medicine and Public Health. 2012;5:569-573.

11. Pravin NY, Keerti SJ. A cross-sectional study on knowledge, attitude and practice on blood donation among medical students of South India. International journal of medical and health sciences. 2013;2:2277-2281.

12. RS Bharatwaj Vk, P Rajaram. A Descriptive Study of Knowledge, Attitude and Practice with regard to Voluntary Blood Donation among Medical Undergraduate Students in Pondicherry, India. JCDR. 2012;6(4).

13. Benedict N. knowledge, attitude and practice of voluntary-blood donation amongphysicians in a tertiary-health facility of a developing country blood disorder and transfusion. 2012.

14. AD Abdul Majeed. Attitude, belief and knowledge about blood donation and transfusion in Saudi population. Pak J Med Sci. 2008;24:74-79.

15. Agrawal A, Tiwari A, Ahuja, et al. Knowledge, attitude and practices of people towards voluntary blood donation in uttarakhand," Asian J Transfus Sci. 2013;7(1):59-62.

16. Ministry of Health, Health Sector Development Program of Ethiopia (HSDP) IV 2010/11-2014/15. 2013.

17. N Mikkelsen. Donor associations, a key link between donors and blood centres," ISBT Science Series 5.N1 (2010). 2009;5(1):12-16. 